\title{
Characterization of ultra-fine aluminium particles with potential applications as composite propellants
}

\author{
K TEJASVI ${ }^{1, *}$ (D), V VENKATESWARA RAO ${ }^{1}$ and Y PYDI SETTY ${ }^{2}$ \\ ${ }^{1}$ Defence Research and Development Organization, Hyderabad 500058, India \\ ${ }^{2}$ National Institute of Technology, Warangal 506004, India \\ *Author for correspondence (tejasvichem@gmail.com)
}

MS received 19 November 2018; accepted 13 March 2019

\begin{abstract}
High performance and reactivity of ultra-fine aluminium is the present new area of interest in aerospace and defence applications. Ultra-fine aluminium is an important ingredient in propellant compositions and formulations, which significantly improves the performance parameters of rockets. This paper discusses the characterization of synthesized ultra-fine aluminium, such as active (metallic) aluminium content, bulk density, X-ray diffraction, surface area (BrunauerEmmett-Teller), scanning electron microscopy, transmission electron microscopy, thermal analysis and X-ray photo-electron spectroscopy. It is observed that the maximum metallic aluminium content of $85.93 \%$ was obtained by a gas volumetric method. The synthesized ultra-fine aluminium particles will greatly promote the application of these particles in composite propellants.
\end{abstract}

Keywords. Ultra-fine aluminium; metallic aluminium content; scanning electron microscopy; gas volumetry.

\section{Introduction}

Aluminium powder is a vital ingredient due to its innate properties like high density, low oxygen consumption and high-combustion enthalpy, which are beneficial for propellant compositions. Ultra-fine aluminium powder is an essential constituent in propellant composition and as an energy additive for a burning reaction. Aluminium is essentially micron-sized, owing to its long ignition delay, slow combustion power and incomplete combustion because its extensive oxidation is viewed as a major obstacle. It has been reported that a decrease in the particle size of aluminium [1] results in an increase in the surface area of the powder and greatly influences its chemical activity and hence, a decrease in activation energy. The use of $\mathrm{Al}$ nanoparticles is preferred because of a significant increase in the surface area and surface energy which aids in obtaining the enhanced burn rate and shorter and reduced ignition delay time [2], which results in improved combustion efficiency [3-5]. It has been reported that there is a significant increase in the burn rate by replacing micronsized aluminium powder with ultra-fine aluminium. Further, it has been found that using ultra-fine aluminium by replacing conventional micron-sized aluminium powder, in the form of aluminium exploded grade, with a particle size ranging from $10-100 \mathrm{~nm}$ in the composite propellant resulted in a decrease in an ignition delay time and an augmented burning rate. Ultrafine aluminium decreases the onset of the high-temperature decomposition temperature of ammonium perchlorate from 392.2 to $372.9^{\circ} \mathrm{C}$ in comparison with micron-sized aluminium powder. Thus, a decrease in the decomposition temperature of ultra-fine aluminium-based compositions augments the burning rate of the propellants [6]. A better combustion efficiency of the ultra-fine aluminized propellant is achievable than that of micron-sized aluminium and it has also been reported that the size and morphology of the combustion product were affected $[7,8]$. Numerous techniques were reported in references for producing ultra-fine aluminium (particle size $<200 \mathrm{~nm}$, such as vapourization/condensation [9,10], plasma recondensation [11], milling [12], chemical method [13], inert gas method [14,15], plasma evaporation method [16] and electro-explosion of wire [17]. These methods paved the way for a number of studies and several researchers on the combustion behaviours of various propellant compositions and formulations containing ultra-fine aluminium powders. Of late, a radio frequency induction plasma (RFIP) process is played a significant role in synthesizing various metal [18-24] powders. RFIP has a unique advantage compared with several methods is that it has no electrodes; hence, contamination of the synthesized powder can be minimized to a great extent. The probable areas of using ultra-fine aluminium in chemical propulsion systems are (i) solid propellant formulations to change the burning rate and variation in pressure and (ii) solid propellant formulations and combinations to reduce agglomeration. Ultra-fine aluminium demands characterization of its properties. One of the most important characteristics of ultra-fine aluminium is active (metal) aluminium content. The reduced metallic $\mathrm{Al}$ content minimizes the oxidation enthalpy, which affects the propellant 
Table 1. Characteristics of the synthesized ultra-fine Al powder.

\begin{tabular}{|c|c|c|c|c|}
\hline Preparation method & Shape & $\begin{array}{c}\text { Mean } \\
\text { diameter }(\mathrm{nm})\end{array}$ & $\begin{array}{l}\text { Thickness of } \\
\text { coating layer }(\mathrm{nm})\end{array}$ & Reference \\
\hline Electro-exploded wire & Sphere & 56.1 & $2-4$ & [27] \\
\hline Plasma synthesized process & Sphere & 57.0 & $2-5$ & \\
\hline Laser heating evaporation & Sphere, rod-like & 51.9 & $3-5$ & \\
\hline Induction heating evaporation & Sphere, rod-like & 44.1 & $3-5$ & \\
\hline $\begin{array}{l}\text { Radio frequency induction plasma } \\
\text { (as procured) }\end{array}$ & Sphere & 126.8 & $1.0-2.5$ & This study \\
\hline
\end{tabular}

performance, such as ideal specific impulse [25]. According to the D2 law, a decrease in the particle size of aluminium reduces the burn time and aluminium oxide content on the surface reduces to significant amounts; thus, the available active metallic $\mathrm{Al}$ content increases [26]. Table 1 shows the characteristics of ultra-fine aluminium powder prepared by other methods. The size of ultra-fine $\mathrm{Al}$ is $100 \mathrm{~nm}-1 \mathrm{~mm}$ and is preferred as a propellant additive since it facilitates complete combustion. In the present work, the determination of metal aluminium in ultra-fine aluminium particles by means of a gas volumetry technique is considered. The ultra-fine aluminium particles synthesized by RFIP characterized through various techniques viz., X-ray diffraction (XRD), energy dispersive analysis by X-rays (EDAX), bulk density (BD), BET surface area, scanning electron microscopy (SEM), transmission electron microscopy (TEM), X-ray photo-electron spectroscopy (XPS) and thermal analysis. The characterization of ultra-fine powders synthesized by RFIP used in propellant manufacturing is performed to understand the effect of the ballistic properties and performance of a solid rocket motor. Thus, this study allows the determination of properties. The advantage of ultra-fine aluminium replacement in solid rockets is double-fold to decrease two-phase losses and an increase in specific impulse $\left(I_{\mathrm{s}}\right)$. Thus, the characterization of ultra-fine aluminium is required to know the actual reactivity as well as to predict and forecast the propellant behaviour with ultra-fine aluminium.

\section{Experimental characterization}

The BD was measured by the conventional method using tap densitometer equipment. An accurately weighed ultrafine aluminium sample $(\sim 8 \mathrm{~g})$ was taken in a $50 \mathrm{ml}$ glass measuring cylinder and the material was tapped to realize a constant value. It took $\sim 40$ strokes to realize the minimum volume. The $\mathrm{BD}$ is given by the formula, $\mathrm{BD}=m / V$, where $m=$ powder mass $(\mathrm{g})$ and $V=$ volume $\left(\mathrm{cm}^{3}\right)$.

SEM enables investigation of the particle morphology. Specimens were observed directly with no surface preparation. In SEM, an electron beam falls on the sample and the sample, in turn, ejects electrons and X-rays. The SEM image is created by detecting the emitted X-rays. SEM was used to study the topography, morphology and the composition of a sample. The large depth of the field of SEM allows the study of the morphology of the sample because of its threedimensional appearance. The SEM uses electron beam than lenses, so it can be operated over a wide range of magnifications. Preparing the sample for SEM needs a lot of special attention, as SEM utilizes vacuum condition for the electron beam to form an image. Therefore, any wet sample must be dried before performing SEM on it, because water (or most other liquids) evaporates in vacuum.

The microstructure of ultra-fine particles was examined using a TEM (Tecnai $\mathrm{G}^{2} \mathrm{FEI}$ ) with an accelerating voltage of $200 \mathrm{kV}$. For the TEM observations, the samples were ultrasonicated in ethanol and then, a drop of each sample was left to dry on a commercial carbon-coated $\mathrm{Cu}$ TEM grid. Thermogravimetric analysis (TGA) was carried out on a SDT Q600 V20.9 Build 20 thermal gravimetric system. The samples were heated at a rate of $10^{\circ} \mathrm{C} \mathrm{min}-1$ with a gas glow of about $100 \mathrm{ml} \mathrm{min}^{-1}$. The changes in energy were surveyed with differential scanning calorimetry (DSC Q20 V24.11 Build 124 instrument). XRD is a non-destructive technique. XRD is used to find information regarding crystal size, strain, chemical composition and physical properties of a material. In XRD, the intensity and the position of the diffracted beam are measured to find the all relevant information. Each crystalline material gives a unique diffraction pattern. One can identify the material by comparing the position and intensity of an unknown material with the diffraction pattern database provided by the Joint Committee for Powder Diffraction Standards (JCPDS). An X-ray beam hits the sample at an angle to the sample surface and the detector is placed in such a way to detect the reflection angle of the X-ray beam. The angle which is formed by the crystallites with the primary beam (X-ray) is called the Bragg's angle. During an experiment, the $\mathrm{X}$-ray beam rotates so as to vary the angle, and the detector also rotates at the same angular velocity, so as to maintain the reflection geometry. XRD measurements are performed using a Philips X-ray diffractometer. A scanning rate of $2^{\circ} \mathrm{min}^{-1}$ at 2000 cycles using $\mathrm{CuK} \alpha$ radiation $(1.54056 \AA)$ is applied. Diffraction angle $v s$. intensity is obtained at the location of the peaks. The sample is loaded in the X-ray diffractometer 
for XRD analysis. XPS spectra of the $\mathrm{Al} 2 \mathrm{~s}, \mathrm{Al} 2 \mathrm{p}, \mathrm{O} 1 \mathrm{~s}$ and $\mathrm{C}$ $1 \mathrm{~s}$ photoelectron lines were recorded using monochromated $\mathrm{AlK} \alpha$ radiation. The surface area measurement is quite important in the application where the material surface plays the key role. In solid propellants, the desirable traits of ultra-fine aluminium are because of its higher surface area. The surface area measurement is performed by the BET method (after Brunauer, Emmett and Teller, 1938) and expressed in $\mathrm{m}^{2} \mathrm{~g}^{-1}$. BET is a well-known and quite simple technique to find the surface area. The working principle for the BET measurement method is the adsorption of gas molecules on the solid surface. Mostly nitrogen is used as the gas because it is inert and available in high purity at reasonable cost. In the present study, a surface area analyser model number Smart Sob 92/93 Instrument finds the surface area. The range of measurement of the instrument is $0.1-2500 \mathrm{~m}^{2} \mathrm{~g}^{-1}$. The particle size distribution of ultra-fine aluminium was determined by a MALVERN2000 particle size analyser based on the static light scattering technique.

Metallic aluminium content is determined as per IS-438 based on the gas evolution method, where the aluminium powder is reacted with sodium hydroxide in a closed system and the liberated hydrogen gas is collected and measured. The volume of gas liberated is depending on the purity/free metallic aluminium content of aluminium powder.

The percentage of metallic aluminium was calculated using the above formula:

$$
\frac{(P-p) \times V \times 273 \times 10000}{(273+T) \times 760 \times 124580 \times M},
$$

where

$P=$ atmospheric pressure of mercury in $\mathrm{mm}$, at the instant measurement of volume of $\mathrm{H}_{2}$ gas,

$p=$ vapour pressure of mercury in $\mathrm{mm}$ of $10 \%$ sodium hydroxide at $T^{\circ} \mathrm{C}$,

$V=$ volume of $\mathrm{H}_{2}$ gas produced in $\mathrm{ml}$,

$T=$ temperature in ${ }^{\circ} \mathrm{C}$ at the instant of measurement of the volume of $\mathrm{H}_{2}$ gas produced,

$M=$ mass of the aluminium powder sample taken for test.

\section{Results and discussion}

The investigated ultra-fine particles were labelled as UFAL. The particles of UFAL were commercial particles produced by the RFIP method, obtained from the known source and were characterized for potential application in composite propellant formulation.

\subsection{Particle size distribution}

The particle size of ultra-fine aluminium was determined by a MALVERN-2000 particle size analyser. The distribution
Table 2. Characteristics of the synthesized ultra-fine Al powder.

\begin{tabular}{lcc}
\hline S1. no. & Particle size distribution & Particle size (nm) \\
\hline 1 & $D_{10}$ & 141 \\
2 & $D_{50}$ & 374 \\
3 & $D_{90}$ & 1309 \\
\hline
\end{tabular}

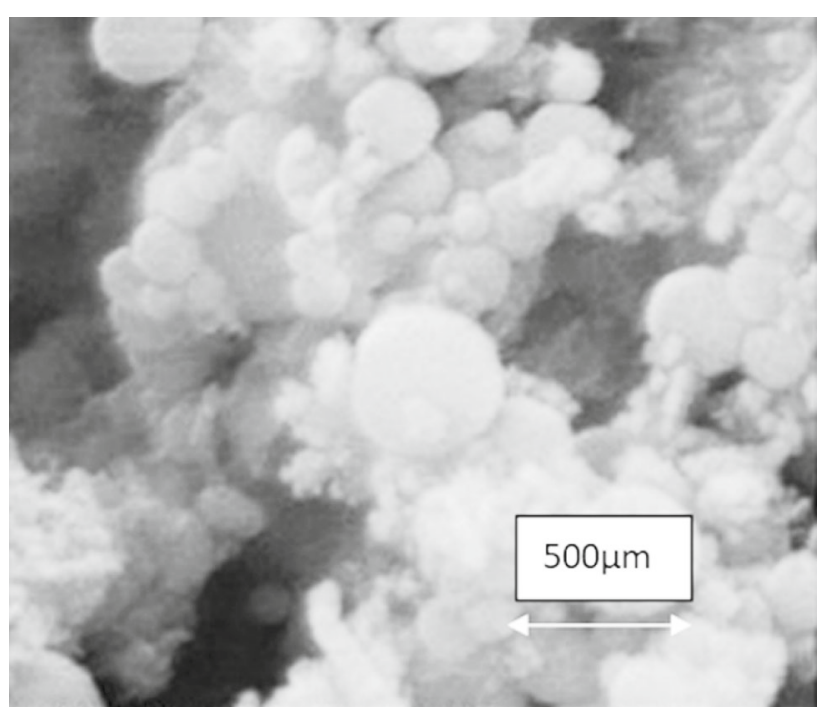

Figure 1. SEM micrograph of UFAP of magnification $80 \mathrm{k} \times$.

of ultra-fine particles $D_{10}$ to $D_{90}$ is varied from 141 to $1309 \mathrm{~nm}$ and is shown in table 2. The data obtained from MALVERN are of a qualitative nature. They provided a reasonable evaluation of the size distribution for the tested powder.

\subsection{Morphology of ultra-fine aluminium powder}

The morphology of the ultra-fine powder was performed on a SEM, and the photographs are shown in figures $1-5$ of different magnifications. The figure reveals the spherical nature of the ultra-fine particles.

\subsection{Determination of active metallic content}

The active metal content of ultra-fine aluminium powder was determined by the gas volumetric method using a $20 \mathrm{wt} \%$ $\mathrm{NaOH}$ solution and on reaction with aluminium powder produced hydrogen gas by the following equation:

$$
2 \mathrm{Al}+2 \mathrm{NaOH}+2 \mathrm{H}_{2} \mathrm{O}=2 \mathrm{NaAlO}_{2}+3 \mathrm{H}_{2} .
$$

The hydrogen gas produced was measured at a standard temperature and pressure, and based on the volume of hydrogen 


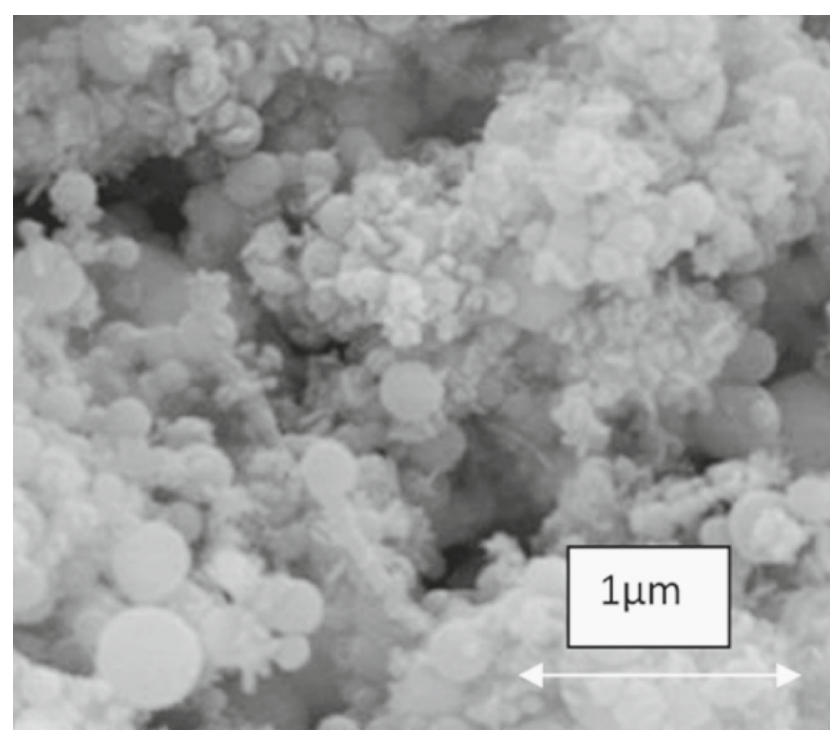

Figure 2. SEM micrograph of UFAP of magnification $50 \mathrm{k} \times$.

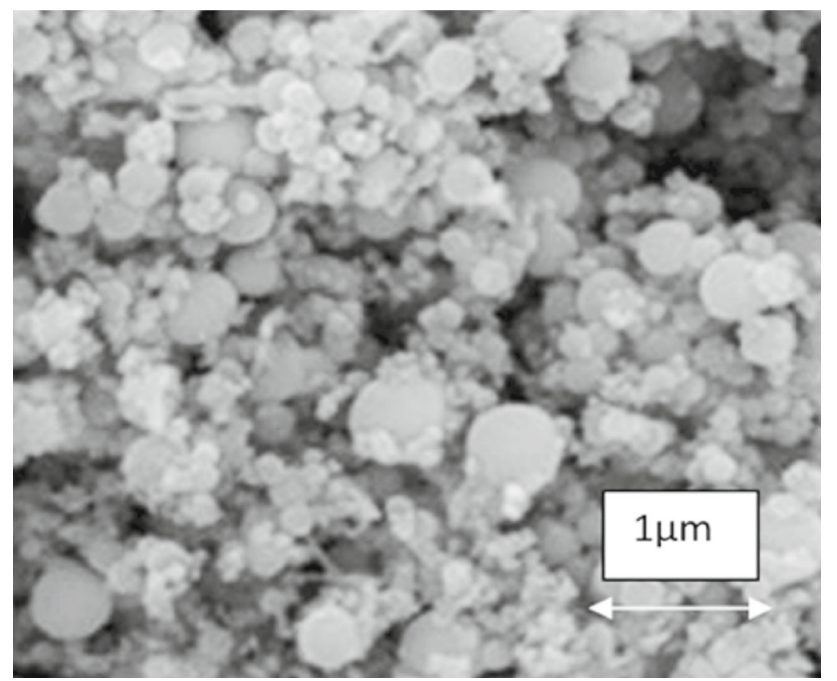

Figure 3. SEM micrograph of UFAP of magnification $30 \mathrm{k} \times$.

gas; the active metal content was calculated. The active metal content for ultra-fine aluminium was found to be in the range of $82-86 \mathrm{wt} \%$ as shown in table 3 . The error in the present analysis is $<0.5 \%$.

\section{$3.4 \quad X R D$}

Ultra-fine aluminium powder was characterized for its purity using the powder-XRD technique. A continuous scanning mode at a scanning rate of $2^{\circ} \mathrm{min}^{-1}$ was adopted. Figure 6 shows the XRD pattern of ultra-fine aluminium. Five characteristic peaks for aluminium $(2 \theta=38.6,44.8,65.2,78.2$ and 82.4), corresponding to Miller indices (111), (200), (220),

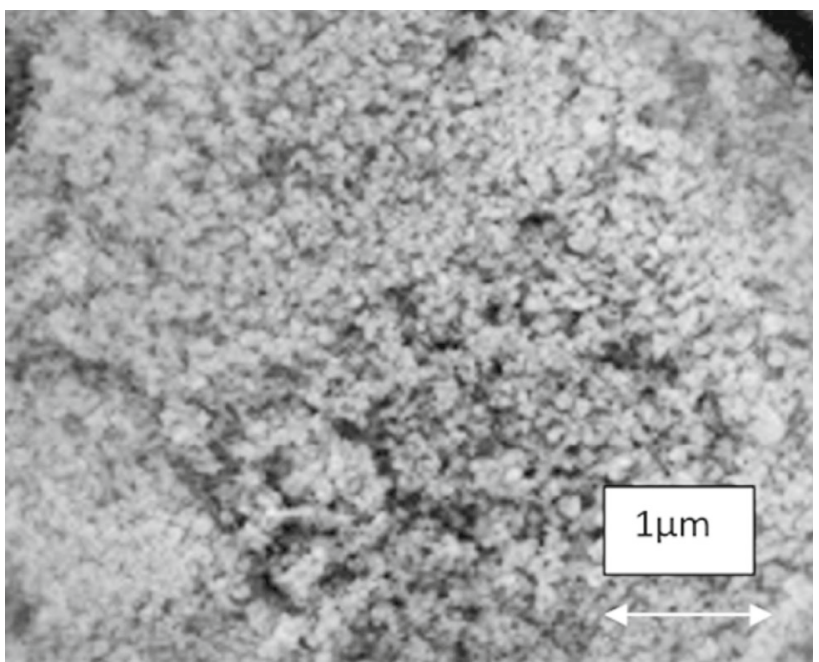

Figure 4. SEM micrograph of UFAP of magnification $5 \mathrm{k} \times$.

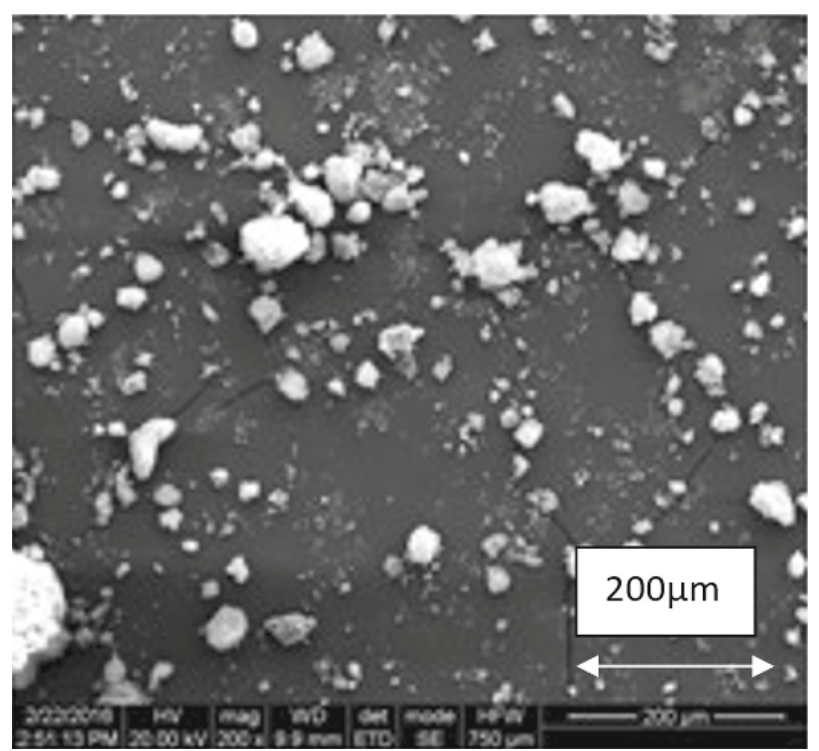

Figure 5. SEM micrograph of UFAP of magnification $200 \times$.

Table 3. Result of metallic Al content.

\begin{tabular}{lcc}
\hline Characteristics & Test method & Test values \\
\hline Appearance of powder & Visual & $\begin{array}{c}\text { Brackish grey fine } \\
\text { powder in } \\
\text { agglomerated form }\end{array}$ \\
$\begin{array}{lll}\text { Metallic aluminium content: } \\
\text { by gas volumetry }\end{array}$ & IS: 438 & \begin{tabular}{c}
$85.93 \%$ \\
\hline
\end{tabular} \\
\hline
\end{tabular}

(311) and (222), were observed. This revealed that the resultant particles were pure face-centred cubic (ICDD: 040787) aluminium. In this pattern, there is no peak related to the aluminium oxide found under the sample, which suggests that the aluminium oxide layer is amorphous. 


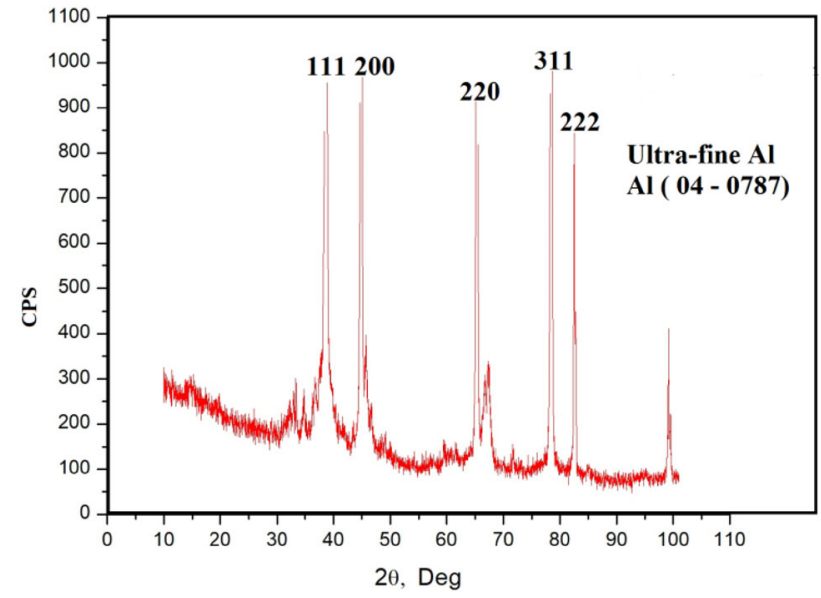

Figure 6. XRD of ultra-fine aluminium powder.

Table 4. Surface area measurement of UFAL.

\begin{tabular}{lccc}
\hline $\begin{array}{l}\text { Aluminium } \\
\text { sample }\end{array}$ & $\begin{array}{c}\text { Surface area } \\
\left(\mathrm{m}^{2} \mathrm{~g}^{-1}\right)\end{array}$ & $\begin{array}{c}\text { Particle size from } \\
\text { BET tests }\end{array}$ & Reference \\
\hline ALEX & 11.3 & 197 & {$[28]$} \\
UFAL & 8.37 & 265 & This study \\
\hline
\end{tabular}

\subsection{Surface area measurement by BET method}

The surface area of the samples obtained from the BET measurement is listed in table 4.

The surface area of the ALEX sample produced by an electrical explosion method is nearer to the value produced by RFIP. The particle size was calculated from the surface area measured by BET technique. This is a very simple technique for calculating particle size compared to TEM or SEM, which is not cost-effective and time consuming.

$$
\text { Average particle size }=\frac{6 \times 1000}{\text { Surface area } \times \text { Density }} .
$$

In the above equation, the average particle size is in $\mathrm{nm}$, surface area is in $\mathrm{m}^{2} \mathrm{~g}^{-1}$ and the density is in $\mathrm{g} \mathrm{cc}^{-1}$. The above equation holds good for the particles of spherical shape. If the particles are not spherical, the above equation varies slightly, which is not included in the present study. In the present study, it is assumed that all the particles are spherical, which is not true for some of the samples tested in the present study. But the variations in the results are not much affected by this assumption.

\subsection{EDAX analysis}

Table 5 represents EDAX analysis carried out for the elemental composition of ultra-fine aluminium. It is observed that
Table 5. EDAX spectroscopic result of the sample.

\begin{tabular}{lrrrrr}
\hline & \multicolumn{2}{c}{ Wt\% } & & \multicolumn{2}{c}{ At\% } \\
\cline { 2 - 3 } \cline { 5 - 6 } Element & This study & [29] & & This study & [29] \\
\hline $\mathrm{O}$ & 9.92 & 5.91 & & 15.66 & 9.58 \\
$\mathrm{Al}$ & 90.08 & 94.09 & & 84.34 & 90.42 \\
\hline
\end{tabular}

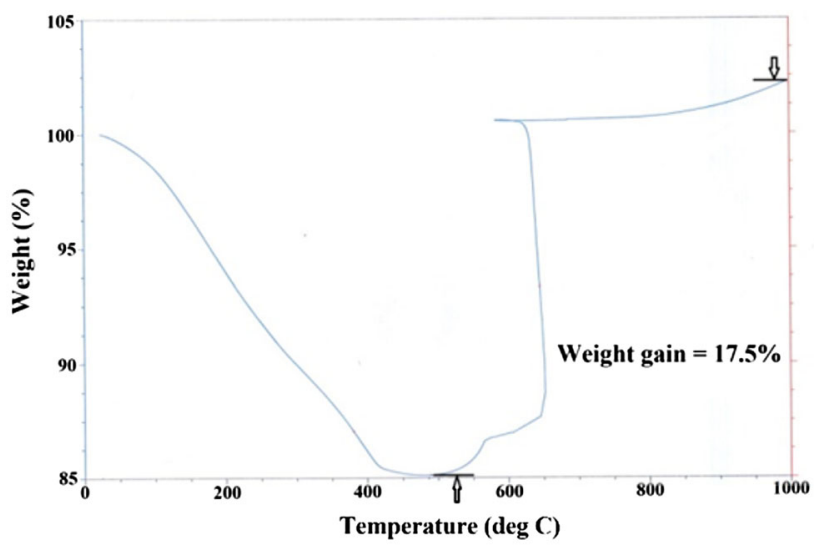

Figure 7. TGA of ultra-fine aluminium powder.

the compositions in the powder samples are aluminium and oxygen. Aluminium nanoparticles produced by other methods such as electrical explosion of wire and the elemental compositional analysis performed by an energy dispersive X-ray spectrometer show the atomic percentage of oxygen nearly $10 \%$, which is having a size range of $20-200 \mathrm{~nm}$ [29].

\subsection{Thermal analysis}

Figure 7 shows the TGA plot of UFAL. Exotherm and mass gains of the sample between the TGA plots demonstrate a weight loss up to $450^{\circ} \mathrm{C}$, which is due to the loss of adsorbed gases, water vapours and passivated from the surface of ultra-fine aluminium particles. Weight gain starts around $500^{\circ} \mathrm{C}$, which continues upto $1000^{\circ} \mathrm{C}$ with an intermediate step around $640^{\circ} \mathrm{C}$. Careful analysis of TGA plots reveals various processes involved in the oxidation of ultra-fine aluminium particles. Oxidation of ultra-fine aluminium particles is mainly governed by (i) chemical kinetics leading to the formation of a surface oxide shell and (ii) diffusion of oxygen leading to the oxidation of core aluminium which are very well discussed in the literature $[27,30]$.

Figure 8 shows the DSC curve for UFAL. Here, we observe that an exotherm of the sample between 480 and $660^{\circ} \mathrm{C}$ is the result of the oxidation of solid aluminium, a phenomenon only observed with ultra-fine particles. The temperature of the oxidation peak $\left(T_{\mathrm{p}}\right)$ and the corresponding enthalpy change is $592.8^{\circ} \mathrm{C}\left(1.9 \mathrm{~kJ} \mathrm{~g}^{-1}\right)$. The UFAL gets highly oxidized even 


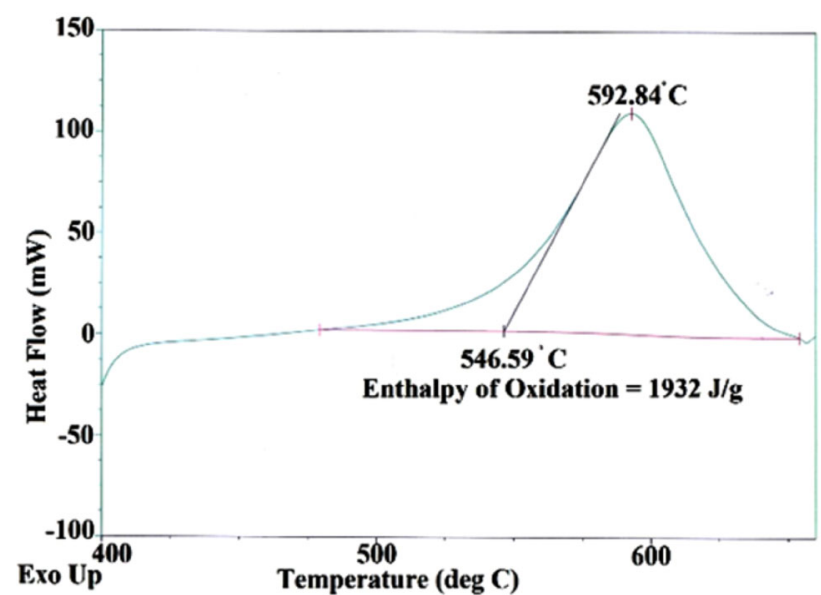

Figure 8. DSC of ultra-fine aluminium powder.

Table 6. XPS result of the sample.

\begin{tabular}{lcc}
\hline Name & Binding energy $(\mathrm{eV})$ & At\% \\
\hline O 1s & 530.5 & 40.27 \\
C 1s & 283.5 & 44.29 \\
Al 2p & 73.0 & 15.44 \\
\hline
\end{tabular}

before melting and leaving a small fraction of molten metal at $660^{\circ} \mathrm{C}$, beyond the melting point, UFAL gets oxidized.

\section{$3.8 X P S$}

XPS profiles allow the investigation of atomic composition as shown in table 6 as a subsurface region and quantification of the concentrations of the main constitutive elements. By considering the whole aluminium peak, there is the possibility of decomposing it in metallic-Al and oxidized-Al components. Figure 9 shows the XPS survey spectrum (recorded with monochromatic $\mathrm{AlK} \alpha$ radiation) and the inset shows the $\mathrm{Al}$ $2 \mathrm{p}$ region recorded at higher resolution showing the metallic $\left(\mathrm{Al}^{\circ}\right)$ and oxide $\left(\mathrm{Al}^{3+}\right)$ components as shown in table 7. Oxide films on ultra-fine aluminium particles are formed during their slow oxidation in air in the course of passivation. The thickness, composition and structure of the passive layer on the particles play an important role during their oxidation, because these parameters determine the diffusion rate of the gaseous oxidizer at low temperatures, and thereby, the ignition temperature. The oxide layer significantly lowers the particle energy density, slows the particle combustion rate and may prevent aluminium consumption.

\subsection{TEM}

Figure 10 shows TEM images of UFAL particles. Figure 10a and $b$ show that the UFAL particles are all spherical with an average size of $126.8 \mathrm{~nm}$ and aggregate together. Figure $1 \mathrm{~b}$

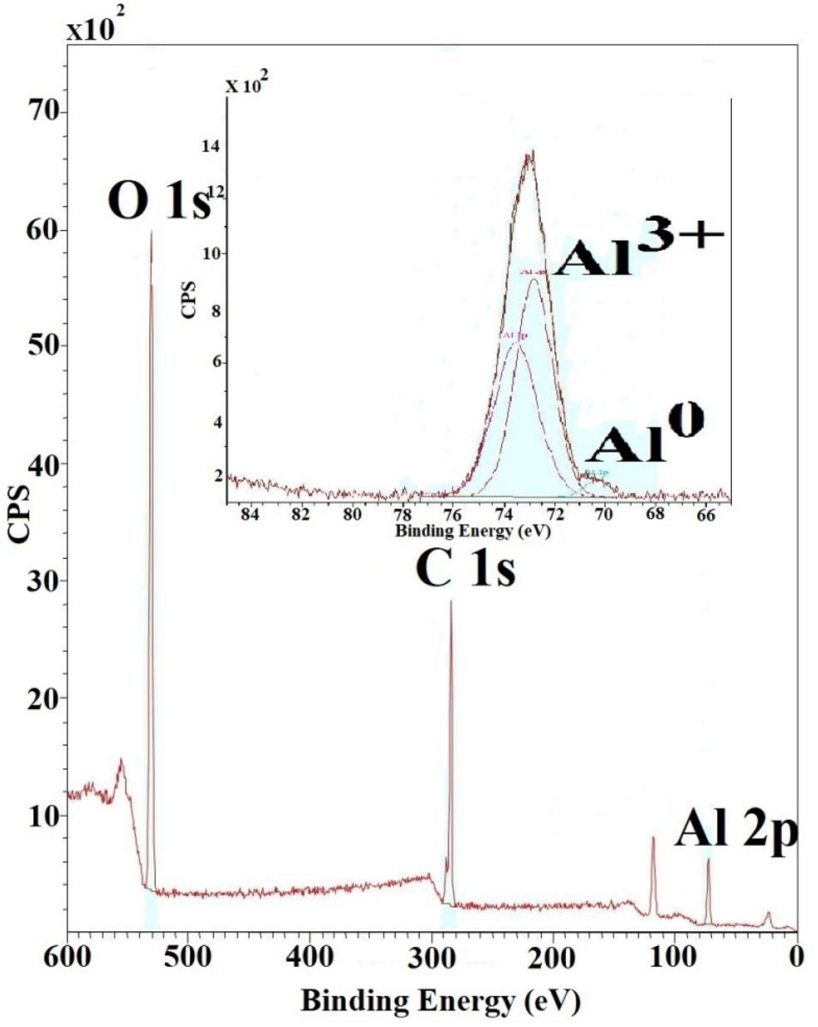

Figure 9. XPS survey spectrum of UFAL.

Table 7. Binding energy result of $\mathrm{Al} 2 \mathrm{p}$.

\begin{tabular}{lc}
\hline Name & Binding energy $(\mathrm{eV})$ \\
\hline Al 2p & 73.54 \\
Al 2p & 70.30 \\
Al 2p & 72.82 \\
\hline
\end{tabular}

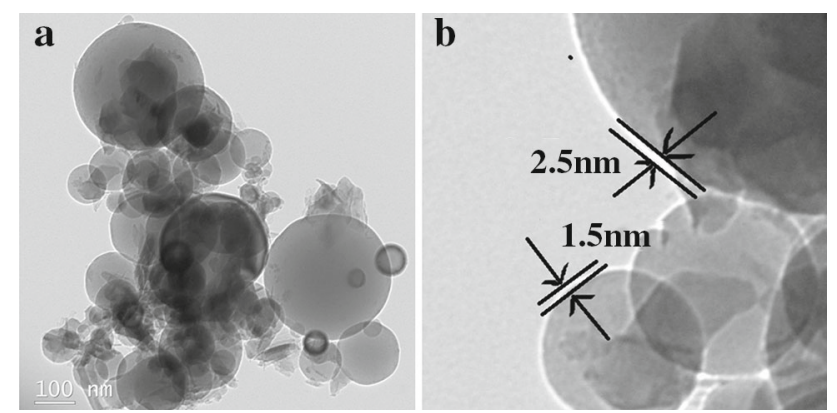

Figure 10. (a and $\mathbf{b})$ TEM images of UFAL particles.

shows that the UFAL particles have a typical core-shell structure and the thickness of the oxide shell layer is 1.50 $\mathrm{nm}$. There are no obvious lattices in the oxide layers, which show an amorphous structure. 


\subsection{Incorporation of ultra-fine aluminium in composite propellants}

Mixing of the composite propellant was carried in batch mode in a vertical planetary mixer. A mixture of pre-polymer resin, plasticizer, antioxidant and bonding agent was mixed in the vertical planetary mixer. The mixture was agitated followed by mixing. Then, ultra-fine aluminium powder was added and mixed thoroughly. After the complete distribution of ultra-fine aluminium powder in the binder matrix, an oxidizer in the bimodal form was added in two proportions and mixed in such a way that homogenous mixing could take place. After the addition of all solid ingredients, further mixing of the composition was carried out. At this stage, curator was added and further mixed. The composition was cast into a mould by vacuum casting, and it was cured. The cured compositions were used for the determination of mechanical and ballistic properties. Ignition of aluminium closer to the surface of the propellant increases the heat feedback to the propellant, which accelerates the decomposition process of the propellant matrix and ultimately, the burning rate. The reduction in the particle size enhances the combustion reaction by several distinct mechanisms. Reduction in the particle mass decreases the transient heat conduction travel time through the particle, and an increase in the surface-to-volume ratio yields better dispersion of the particles in the propellant, thereby increasing the reactant sites. Finally, the ultra-scale particles can have completely different surface chemistry, often better than their micron-sized counterparts.

\section{Conclusions}

The synthesized ultra-fine aluminium powder obtained from a RF induction plasma technique was characterized by numerous investigation techniques viz., surface area, morphology and chemical species characteristics demonstrating highly crystalline spherical particles. A maximum metallic aluminium content of $85.93 \%$ was achieved by a gas volumetry technique. XRD patterns suggest that the aluminium oxide layers on these particles are amorphous. The TGA results reveal that there is a weight gain of $17.5 \%$ and exothermic characteristics are seen through DSC. The TEM results show that the UFAL particles have a core-shell structure on the surface of UFAL with an average thickness of $1.5 \mathrm{~nm}$. This strongly demonstrates that this powder is best suitable for propellant compositions.

\section{Acknowledgements}

We gratefully thank Director ASL, for facilitating this research work.

\section{References}

[1] Eisenreich N, Juez-Lorenzo M, Kolarik V, Koleczko A, Weiser V and Fietzek H 2004 Propell. Explos. Pyrot. 29137

[2] Jayaraman K, Chakravarthy S R and Sarathi R 2010 Combust. Explos. Shock Waves 4621

[3] DeLuca L T, Colombo G, Maggi F, Bandera A, Babuk V A, Galfetti L et al 2010 J. Propul. Power 26724

[4] Ivanov Y F, Sedoi V S, Arkhipov V A, Bondarchuk S S, Vorozhtsov A B, Korotkikhand A Get al 2003 Propell. Explos. Pyrot. 28319

[5] Jayaraman K, Chakravarthy S R, Anand K V and Sarathi R 2009 Combust. Flame 1561662

[6] Li F, Guo X, Liu L, Li M, Chen W, Jiang W et al 2011 Int. J. Energ. Mater. Chem. Propul. 1067

[7] Babuk V, Dolotkazin I, Conti A, Galfetti L, DeLuca L T, Glebov A et al 2009 Prog. Propuls. Phys. 13

[8] Galfetti L, Severini F, Colombo G, Meda L, DeLuca L T and Marra G 2007 Eur. Conf. Aerosp. Sci. EUCASS 1126

[9] Jigatch A N, Kuskov M L, Stoenko N I, Storozhev V, Leipunsky I O and Pribory B 2002 Exp. Tech. Instrum. 6122

[10] Ya G M and Miller A V 1981 USSR inventor's certificate no. 814432 Byull. Izobret no. 11

[11] Mazalov Y A, Bogdanova V V, Ivashkevich L S, Pavlovets G Y and Chinnov V V 1993 Combust. Explos. Shock Waves 29 198

[12] Khan A S, Farrokh B and Takacs L 2008 Mater. Sci. Eng. A 48977

[13] Haber J A and Buhor W E 1998 J. Am. Chem. Soc. 12010847

[14] Gutmanas E Y, Trusov L I and Gotman I 1994 Nanostruct. Mater. 4893

[15] Sanchez-Lopez J C, Caballero A and Fernandez A 1998 J. Eur. Ceram. Soc. 181195

[16] Sun X K, Sun M, Cong H T and Yang M C 1999 Nanostruct. Matter 11917

[17] Sedoi V S and Valveich V V 1999 J. Tech. Phys. 2581

[18] Girshick S L, Muno R, Wu C Y, Yang L, Singh S K, Chiu C P et al 1993 J. Aerosol. Sci. 24367

[19] Kobayashi N, Kawakami Y, Kamada K, Li J G, Watanabe R and Ishigaki T 2008 Thin Solid Films 5164402

[20] Mamak M, Stadler U, Dolbec R, Boulos M, Choi S Y and Petrov S 2010 J. Mater. Chem. 209855

[21] Jung T, Kwon H, Park S, Ho J, Jung S, Baek J et al 2015 J. Nanosci. Nanotechnol. 158424

[22] Ananthapadmanabhan P V, Sreekumar K P, Thiyagarajan K and Venkatramani N 2004 Scr. Mater. 50143

[23] Ye R, Li J G and Ishigaki T 2007 Thin Solid Films 5154251

[24] Kim K I, Kim J H, Cho W S, Hwang K T, Choi S C and Han K S 2014 Ceram. Int. 408117

[25] Dreizin E L 2009 Prog. Energy Combust. Sci. 35141

[26] Maggi F, Paravan C, DeLuca L T, Dossi S and Liljedahl M 2015 Powder Technol. 27046

[27] Chen L, Song W, Lv J, Chen X and Xie C 2010 Mater. Chem. Phys. 120670

[28] Gromov A A, Strokova Y I and Ditts A A 2010 Russian J. Phys. Chem. 4156

[29] Wang F, Wu Z, Shangguan X, Sun Y, Feng J, Li Z et al 2017 Sci. Rep. 75228

[30] Wang S 2005 Propell. Explos. Pyrot. 30148 